\title{
Sensitivity to Parenting in Adolescents with Callous/Unemotional Traits: Observational and Experimental findings
}

\author{
Thomas G. O’Connor, Sajid Humayun, Jackie A Briskman, and Stephen Scott
}

\begin{abstract}
Thomas G. O’Connor, Wynne Center for Family Research, Department of Psychiatry, University of Rochester Medical Center; Sajid Humayun, Department of Psychology, University of Greenwich; Jacqueline A. Briskman and Stephen Scott, King's College London Institute of Psychiatry Psychology and Neuroscience.

This research was funded by research Grant 1206/2491 from the Healthcare Foundation.

Correspondence concerning this article should be addressed to Thomas G. O'Connor, Wynne Center for Family Research, Department of Psychiatry, University of Rochester Medical Center, 300 Crittenden Boulevard, Rochester, NY 14642. E-mail: tom_oconnor@urmc.rochester.edu or to Stephen.Scott@kcl.ac.uk
\end{abstract}

Online First Publication, April 7, 2016. http://dx.doi.org/10.1037/abn0000155

CITATION

O’Connor, T. G., Humayun, S., Briskman, J. A., \& Scott, S. (2016, April 7). Sensitivity to Parenting in Adolescents With Callous/Unemotional Traits: Observational and Experimental Findings. Journal of Abnormal Psychology. Advance online publication. http://dx.doi.org/10.1037/abn0000155 


\begin{abstract}
Children and adolescents with callous-unemotional (CU) traits have been distinguished as a subset of individuals with disruptive behavioral disorders who may be less sensitive to parenting influence; we test this hypothesis using multiple methods and assessment paradigms. 271 adolescents (mean age 12.6 years) from three samples at elevated risk for disruptive behavior disorders were studied. Symptoms of callous-unemotional (CU) behavior were derived from standard questionnaire; assessments of behavioral adjustment were derived from clinical interview with parent, and parent-, teacher-report, and self-report questionnaire. Parent-child relationship quality was based on observational assessments in which adolescent and parent behaviors were rated in three interaction tasks: a) low conflict planning task; b) problem-solving conflict task; c) puzzle challenge task; parent interview and parent- and child-report questionnaires of parenting were also assessed. Results indicated that the associations between parent-child relationship quality and behavioral adjustment were comparable in adolescents with and without CU traits. More notably, observational data indicated that adolescents with elevated CU traits showed comparatively greater within-individual variability in observed angry/irritable behavior across interaction tasks, suggesting greater sensitivity to and emotional dysregulation in challenging interpersonal contexts. The findings suggest that adolescents with CU are not less sensitive to parental influence and may in contrast show greater context-sensitive disturbances in emotional regulation. The results have implications for family-based assessment and treatment for adolescents with disruptive behavior disorders.
\end{abstract}

Key words: disruptive behavior disorders, callous-unemotional traits, emotional regulation, parent-adolescent observations, within-individual variability 


\section{Sensitivity to Parenting in Adolescents with Callous/Unemotional Traits: Observational and Experimental findings}

The presence of callous-unemotional (CU) traits is a specifier for Conduct Disorder in DSM- 5 because of the considerable research literature identifying psychological and biological distinctions of children with CU traits (P. J. Frick, Ray, Thornton, \& Kahn, 2014) and mounting evidence that this subset of children has a particularly severe and persistent disturbance (McMahon, Witkiewitz, Kotler, \& Conduct Problems Prevention Research, 2010; Pardini \& Fite, 2010). In terms of clinical and public health significance, one of the more striking hypotheses about young people with $\mathrm{CU}$ traits is that they may be less - or differentially - susceptible to caregiving influence. The current study builds on and extends this hypothesis using extensive observational data and multiple methods and assessment paradigms.

Evidence suggesting that children and adolescents with CU traits may be less sensitive to caregiving influence derives from three lines of evidence. One indirect line of evidence is the strong genetic influence on CU traits (Blonigen, Hicks, Krueger, Patrick, \& Iacono, 2006; Larsson, Andershed, \& Lichtenstein, 2006; Tuvblad, Wang, Bezdjian, Raine, \& Baker, 2015) and the finding that, among those children with disruptive behavioral disorders, there may be a stronger genetic component in the subset with CU traits (Viding, Jones, Frick, Moffitt, \& Plomin, 2008). More direct evidence derives from studies showing that CU traits moderate associations between a range of parenting dimensions and behavioral adjustment. For example, in a sample of 9-10 year-olds, Yeh and colleagues (Yeh, Chen, Raine, Baker, \& Jacobson, 2011) found that children's reporting of both positive and negative parenting were more strongly associated with self-reported reactive aggression in children with low versus high levels of psychopathic traits. A study of young clinic-referred children (Pasalich, Dadds, Hawes, \& 
Brennan, 2011) found that coercive parenting was more strongly associated with conduct problems in children with low compared with elevated levels of $\mathrm{CU}$; other studies suggest that disciplinary practices may be more weakly associated with behavioral problems in children with elevated CU traits (Oxford, Cavell, \& Hughes, 2003; Wootton, Frick, Shelton, \& Silverthorn, 1997). A third line of evidence is from intervention studies showing that CU traits may be associated with weaker perceived response to punishment such as time-out (Hawes \& Dadds, 2007), and that children with elevated CU traits may be less responsive to intervention (Spain, Douglas, Poythress, \& Epstein, 2004).

The hypothesis that children and adolescents with CU traits are less sensitive or susceptible to parental influence has attracted considerable momentum because it may translate into a clinical and developmental context those distinguishing neurocognitive and affective features of CU, including insensitivity to punishment cues (Fisher \& Blair, 1998), poor emotion recognition (Blair, Colledge, Murray, \& Mitchell, 2001), decreased fearfulness (Barry et al., 2000; Viding et al., 2012), low physiological arousal (Loney, Butler, Lima, Counts, \& Eckel, 2006), reduced fear and disturbances in amygdala activation when processing fearful expressions (Marsh et al., 2008), and pre-attentive fear-recognition deficits (Sylvers, Brennan, \& Lilienfeld, 2011). It is not yet clear how or if these neurocognitive characteristics link with quality of parent-child relationships, but these findings imply that parenting experiences may be differently perceived by children with and without CU traits.

However, not all studies support the hypothesis that children and adolescents with elevated CU traits are less sensitive to parenting influence. For example, CU traits have been reliably associated with caregiving experiences (Pardini, Lochman, \& Powell, 2007; Waller et al., 2012); furthermore, not all studies find that the associations between parenting and child 
behavioral adjustment are moderated by CU, e.g. (Waller et al., 2014), or that CU traits moderate treatment response to intervention (Kolko \& Pardini, 2010). More notable contrary findings include the observation that caregiving quality predicts CU stability (P. J. Frick, Kimonis, Dandreaux, \& Farell, 2003); parental warmth may have a stronger association with problem behavior in children with elevated levels of CU traits (Kroneman, Hipwell, Loeber, Koot, \& Pardini, 2011); and children with CU traits may be more sensitive to coercive parenting for proactive aggression (Yeh et al., 2011). These findings are significant in raising an alternative hypothesis that children with CU traits may, in certain circumstances, show greater sensitivity or responsiveness to caregiving.

The inconsistent pattern of results so far reported may indicate no robust overall effect. Nonetheless, the hypothesis holds substantial implications for understanding the social mechanisms of psychopathy and its assessment and treatment, thereby underscoring the need for further research on this hypothesis.

Deciphering whether or not children and adolescents with CU traits are differentially sensitive to parental influence compared with those without $\mathrm{CU}$ traits has been difficult to resolve because of the variation in operationalizing "sensitivity." We extend prior research by operationalizing "sensitivity" in several ways. First, consistent with prior research, we test the robustness of associations between CU traits and parent-child relationship quality, and the extent to which $\mathrm{CU}$ traits moderate the prediction from caregiving to behavioral adjustment. For these analyses we rely on data from multiple sources to address concerns about shared method variance that may confound results.

An alternative and more novel method exploits the power of a within-subject design to examine adolescents' behavior with parents across interaction contexts which vary in 
interpersonal and parenting demands. In the current study, adolescent behavior toward the parent was assessed in the standard "hot topic" problem-solving conflict interaction (Hetherington \& Clingempeel, 1992) as well as in two alternative settings: a low-conflict "plan a holiday" task and a mildly challenging puzzle task which was not relationship conflict-focused. This experimental manipulation varies the interpersonal stress and is analogous to studies of mood induction and emotional regulation (Musser et al., 2011) and with prior research on disruptive behavioral disorders across interpersonal settings (Wakschlag et al., 2008). Observed behaviors indicating anger/irritability and warmth/engagement were coded in each of the three settings by raters blind to all clinical and diagnostic data. If adolescents with CU show less sensitivity to caregiving, then we might expect less variability in behavior across setting compared with adolescents without CU, e.g., because of a lack of arousal or reduced ability to attend and respond to the caregiver across low- and high-conflict settings. The contrary hypothesis is that difficulty in emotional regulation, amplified in a conflict setting, and coupled with deficits in empathy or emotional understanding required in problem-solving negotiations, may make problem-solving negotiation tasks comparatively more frustrating for adolescents with elevated CU traits. If that were so, then adolescents with elevated CU traits might be most distinguishable, in terms of their angry/irritable behavior, in the problem-solving interaction. We test this novel hypothesis.

\section{Method}

\section{Participants}

The sample for the current study is composed of adolescents drawn from three independent samples; the three samples were pooled to improve statistical power and because identical procedures and methods were used to assess psychopathology and adolescent-parent 
interactions. The first is a high-risk clinic sample which included youths aged 9-17 years who were referred to mental health clinics in South London and Sussex aged 3-7 years because of antisocial behavior (Scott, Spender, Doolan, Jacobs, \& Aspland, 2001); 107 of 141 original families were successfully followed-up in adolescence. The second is a moderate risk community sample, which was composed of youths aged 9-13 years who were originally studied as part of a treatment trial aged 4-6 years because of elevated conduct problems (Scott et al., 2010); 102 of 128 families in the original study were successfully followed-up in adolescence. A third sample is a foster sample recruited via Social Services' computerized records from the Children's Services Departments of two London boroughs (Joseph, O'Connor, Briskman, Maughan, \& Scott, 2014) ${ }^{1}$. Families were eligible to take part in the study if the adolescent had been living in the family for at least 5 months (to allow for adjustment to the new placement), was aged 10-16 years, and not in kinship care. One hundred and sixty four families fulfilled inclusion criteria and were contacted by letter via Children's Services; 62 families consented to take part in the study. The main reasons for refusal to take part in the study were imminent placement breakdown (10\%), lack of interest (13\%), foster parent concern that participation might adversely affect the child (16\%), and lack of time to participate (13\%); $16 \%$ of carers gave no reason for not participating. Sample characteristics are provided in Table 1 for the total sample and for each at-risk/clinic sample.

All adolescents did not have recognized developmental delay and were fluent in English. Written consent from mother and assent from the child was obtained; the study was approved by the local research ethics committee. Parents were paid $£ 20$ for participation; adolescents were paid $£ 10$.

\footnotetext{
${ }^{1}$ A sample of normal-risk community sample of adolescents was recruited as a comparison sample for the foster care sample; however, none of the normal-risk community adolescents exhibited elevated levels of callousunemotional symptoms and so they were not included in the current analyses.
} 


\section{Procedures}

Adolescents and parents were visited in the home by two research assistants. The interviewers first obtained consent from the parent and adolescent and then administered interview and questionnaire assessments to collect demographic, psychosocial, and psychiatric data; the observational assessment was conducted early in the course of the home visit. For the observational assessment, parents and adolescents were asked to complete three observational tasks which were chosen to simulate differential levels of conflict and interpersonal demands. The first was a planning task in which the parent and adolescent were asked to plan an imaginary family holiday for $£ 500$; the task, which lasted 5 minutes, was administered as a low-conflict task. The second task, designed to evoke high interpersonal conflict, was the standard "hot topic" problem-solving interaction in which the parent and adolescent were asked to discuss and resolve the two most common sources of relationship conflict that were identified from a questionnaire assessment (Hagan, Hollier, O'Connor, \& Eisenberg, 1992); participants were instructed to spend 5 minutes on each conflict topic. The third task consisted of a 5-minute puzzle task in which the parent and adolescent were asked to solve a challenging magnetic puzzle with minimal direction or explanation; this interaction was designed to be challenging but did not target interpersonal conflict. The tasks were delivered in this order for all participants. For each task, the research assistant briefly introduced the task and then left the room. All interactions were videotaped for later coding (see below).

\section{Measures}

Callous-Unemotional traits. Callous-Unemotional (CU) traits were assessed from parent reports on the Antisocial Process Screening Device (APSD) (P. J. Frick, \& Hare, R.D., 2001). The APSD and the CU subscale in particular have been extensively validated in 
developmental and clinical research (P. J. Frick \& Viding, 2009; Sylvers et al., 2011; van Zwieten et al., 2013), and have been shown to predict subsequent outcomes, e.g., (Wymbs et al., 2012), including the prediction to adult arrests, e.g.,(McMahon, Witkiewitz, \& Kotler, 2010). Given the focus on $\mathrm{CU}$ in research on sensitivity or susceptibility to parenting influence, analyses below focus on the $\mathrm{CU}$ scale; select analyses of the total scale are reported as supplementary. Internal consistency of the 6-item parent-reported CU scale was .75; the average inter-item correlation was .33. Categorical assessments of CU have used several cut points to indicate severe disturbance on the 6-item (12 point) scale; a score of 7 or greater (Barry et al., 2000), which corresponds to the $90^{\text {th }}$ percentile in a normative sample (P. J. Frick, \& Hare, R.D., 2001), is used for descriptive purposes (Table 1) or for illustrative purposes (Figure 1; see below). The APSD also includes two additional scales, Narcissism and Impulsivity, which are moderately-highly correlated with the CU scale (r's >.6); these dimensions have attracted substantially less attention than the $\mathrm{CU}$ scale in the literature on sensitivity to caregiving and are therefore not the target of analyses below.

Disruptive and antisocial behavior. Disruptive behavior was measured using multiple methods and sources. Diagnostic symptoms and diagnosis of disruptive behavior were derived from the Child and Adolescent Psychiatric Assessment (CAPA; DSM-IV version), a semistructured diagnostic interview with parents (Angold \& Costello, 2000). Interviewers were extensively trained by the instrument developers. We focus on ODD in the analyses (see Table 1); the rate of diagnosed $\mathrm{CD}$ was too low for meaningful analyses. Mean intra-class correlation reliability on 20 ODD cases was 0.85 (range $0.78-0.93$ ).

In addition, parents and teachers completed the Strengths and Difficulties Questionnaire (SDQ), a widely used brief symptom measure with considerable reliability and clinical validity 
(A. Goodman \& Goodman, 2009; R. Goodman \& Scott, 1999). Analyses focus on the conduct problems scale. In addition, the SDQ has a Psychopathy scale (need help on filling this in; is this the 6-item scale from moran et al JAACAP 2009); items are: ?........ The correlation between the SDQ Psychopathy scale and the APSD CU scale was $\mathrm{r}(235)=.81, \mathrm{p}<.001$. We include in the supplementary analyses section select analyses using this alternative scale to examine the robustness of the pattern of findings on CU.

The Self-Report Delinquency instrument (Mcara, 2005; Smith, 2003) is a widely-used measure assessing adolescent reports of antisocial acts at home (6 questions, e.g., staying out late) and at school (10 questions, e.g., skipping school) plus substance abuse (8 questions). In the current paper we focus on the delinquency volume scale, which provides a broad index of selfreported delinquent acts across setting. Anything to add here???

Observed adolescent-parent interaction quality. Parent and adolescent behaviors in the three interactions were coded using a global observational coding system with an extensive history in family research (Hagan et al., 1992; Hetherington \& Clingempeel, 1992; Scott, Briskman, Woolgar, Humayun, \& O'Connor, 2011). Specific global codes were warmth/support, communication, assertiveness, involvement, anger/rejection, and coercion. Each dimension was coded on a 5-point Likert scale that best reflected the participant's overall behavior in each interaction task. Reliability of the parent and adolescent ratings was made by two researchers who were trained in the system and were blind to all identifying information and other data. Consistent with prior studies (Hagan et al., 1992), a factor analysis led to two factors: a Warmth/Engagement positive factor comprised warmth/support (reliability by intraclass correlation: parent 0.82 , child 0.84$)$, communication $(0.81,0.80)$, assertiveness $(0.92,0.53)$ and involvement $(0.75,0.74)$; an Angry/Irritable negative factor comprised anger $(0.75,0.71)$ and 
coerciveness $(0.67,0.70)$.

Parenting measures from interview and questionnaire. The Five Minute Speech Sample (FMSS) is a widely-used interview measure of parenting in which parents are asked to discuss the child for 5 minutes (Caspi et al., 2004; Scott et al., 2011). Positive and negative expressions of emotional tone are independently rated. ICC reliability for two coders on 20 interviews was .92 for negative comments and .93 for positive comments; analyses below focus on the ratio of positive to negative comments.

Questionnaire measures of parenting from child and parent self-report were based on the Alabama Parenting Questionnaire, a widely-used measure with demonstrated reliability and validity (P.J. Frick, Christian, \& Wootton, 1999). We focused on the subscales that index parenting dimensions most often included in research on children and adolescents with $\mathrm{CU}$ traits, specifically, the Poor Monitoring, Inconsistent Discipline and Positive subscales.

Covariates. Psychosocial and socio-demographic covariates included adolescent gender and age, study membership (dummy coded for each of the three samples), child ethnicity (coded minority/non-minority), maternal education (dichotomized according to whether or not the mother left formal school at age 16 years), history of parenting intervention, single-parent status, qualification for free school meals, and family income. We also include adolescent self-reports of depressive symptoms using the Moods and Feelings Questionnaire, a widely used index of depressive symptoms with considerable evidence of reliability and validity (Angold et al., 1995)

\section{Data analysis}

We first report descriptive data on the study variables across samples. The first set of analyses to test the sensitivity to parental influence hypothesis examines bivariate associations between CU traits and relationship quality measures across multiple methods; disruptive 
behavior is included as a covariate to discern if there are associations particular to $\mathrm{CU}$ unconfounded by general conduct problems. The second set of analyses uses a regression model to test the hypothesis that $\mathrm{CU}$ traits moderate the associations between parenting and conduct problems. The primary outcome variables are disruptive behavior according to parent and teacher reports and adolescent self-reported delinquency; adolescent gender, age, maternal education, and sample are included as covariates in the regression analyses on an a priori basis. For the above analyses, the key observational measure of parenting is the problem-solving interaction because that is the standard observational methodology; we also consider measures of parenting from parent interview and parent- and child-reported questionnaires. For the third, more novel set of analyses to examine the sensitivity to parental influence hypothesis we examine within-individual variability in observed adolescent behavior across the three interaction tasks using repeated measures MANOVA. In this analysis task is a within-subject variable; between-subjects factors include CU traits and the same set of covariates that we used in the regression analyses. A statistical interaction between task and $\mathrm{CU}$ traits indicates that $\mathrm{CU}$ is differentially associated with observed adolescent behavior across the three interaction contexts. Given the prior clinical research focus on anger, irritable, and dysregulated behavior, we target observed adolescent angry/irritable behavior, but we also report analyses for warmth/engaged positive behavior and for parent behavior. All nalyses testing the hypothesis that adolescents with CU traits may be less or differentially susceptible to caregiving influence are based on the continuous measure of CU; only for descriptive (Table 1) or illustrative (Figure 1) purposes do we report findings using a dichotomized measure of $\mathrm{CU}$.

\section{Results}


Of the 271 adolescents included in the study, any observational data were available on $228(84 \%)$. The sample on whom we did not obtain observational data were older (13.23 years $[\mathrm{SD}=1.96]$ versus 12.44 years [1.95, $\mathrm{p}<.05]$; missing observational data was also more common in the clinic-referred $(19.6 \%)$ and community (17.6\%) samples than the foster care sample (6.5\%), $\mathrm{p}<.05$. However, absence of observational data was not associated with parent-reported ODD from interview, parent-reported CU symptoms, or parent or teacher reports of conduct problems on the SDQ; neither was missing observational data associated with child ethnicity or key socio-demographic risks such as maternal education.

Sample descriptive data (Table 1) indicate that children all three samples are at high psychosocial risk and exhibit comparatively high rates of clinical disturbance. Differences across study or sample membership were detected for several socio-demographic factors; therefore, study membership is considered as a covariate alongside adolescent age and gender and maternal education. None of the other covariates listed above was reliably associated with outcomes in the analyses below after controlling for study sample, adolescent age and sex, and maternal education.

\section{Are CU traits reliably associated with parenting and parent-child relationship quality?}

Table 2 shows the bivariate associations between CU traits and parent-child relationship quality across multiple methods; also provided is the association after controlling for parentreported conduct problems. Results indicate generally modest effect sizes but consistent associations across multiple methods. Importantly, multiple measures of parent-child relationship quality remain significantly associated with CU traits even after accounting for conduct problems (although the magnitude of effect size is reduced), implying a robust and particular association between parenting measures and CU traits. In Appendix I we provide an 
extended correlation matrix between parent-child relationship quality measures and $\mathrm{CU}$ and conduct problem scales.

\section{Do CU traits moderate the associations between caregiving and conduct problems?}

Table 3 reports results from regression models in which $\mathrm{CU}$ is examined as a moderator of the association between parent-child relationship quality and disruptive behavioral problems. Given the extensiveness with which parent-child relationship quality and conduct problems were measured, there are many possible moderation models that could be analyzed. Models results from key measures of disruptive behavior and from alternative measures of parenting are provided in Table 3 (results from all models are available from the authors). After controlling for adolescent gender and gender, maternal education, and sample, there was comparatively little evidence that $\mathrm{CU}$ traits moderated the association between parenting and disruptive behavior. Moreover, of the few interactions that were detected, the majority suggested that the association between parenting and disruptive behavior was stronger in adolescents with elevated CU traits. For example, for the model predicting teacher-reported conduct problems, we obtained a significant interaction between observed maternal Warmth/Engaged and Adolescent CU traits (b $=-1.06, \mathrm{p}<.01$; Table 3). Follow-up analyses using the categorical cut-off for CU traits (for illustrative purposes) indicated that the association between observed maternal Warmth/Engaged behavior and teacher-reported conduct problems was significantly stronger among those high on CU traits $(r(26)=-.39)$ than among those low on CU traits $(r(138)-.15)$, controlling for adolescent age, gender, sample, and maternal education. Of the three other significant interactions, only one (predicting adolescent Self-Reported Delinquency from parent-reported Poor Monitoring, Table 3) indicated that the association between parenting and adolescent behavioral adjustment was significantly weaker in individuals with high $(\mathrm{r}(36)=.19)$ versus low 
$(\mathrm{r}(174)=.27) \mathrm{CU}$ traits, after controlling for adolescent age, gender, sample, and maternal education. That is, only four interactions were detected, and in three of these the association between parenting and adolescent behavioral adjustment was stronger among those adolescents with elevated CU traits.

\section{Do adolescents with elevated CU traits show sensitivity to parent-child interaction context?}

Appendix II displays correlations between parent and adolescent behavior across the three interaction tasks. Table 4 displays the means (SD) in adolescent and parent behavior across the three interaction tasks, from which effect sizes may be derived. For adolescents, there was a significant within-subjects or task effect on Angry/Irritable behavior $(\mathrm{F}(2,218)=51.00, \mathrm{p}<.001)$; means (SD) across the three settings indicate that Angry/Irritable behavior was significantly greater in the problem-solving task than the planning task $(\mathrm{t}(221)=7.80, \mathrm{p}<.001)$ and puzzle task $(t(221)=10.24, \mathrm{p}<.001)$, which did not differ from each other $(\mathrm{t}(221)=1.65, \mathrm{p}<.01)$. The tendency for the problem-solving interaction to evoke more angry/irritable behavior from adolescents was notable: the effect size difference in adolescent angry/irritable behavior between the problemsolving and planning task was nearly $3 / 4$ of a standard deviation (.72). In contrast, there was not a task effect on observer-rated adolescent Warmth/Engagement behavior across task $(\mathrm{F}(2,218)=.33)$

A novel approach to testing the sensitivity hypothesis is to examine if adolescents with elevated CU traits also show variability in their behavior across parent-adolescent interaction task which vary in challenge or interpersonal "press." For this analysis, we extended the repeated measures analysis of variance model to include $\mathrm{CU}$ traits as a between-subjects predictor of observed adolescent behavior; also included as covariates were adolescent gender and age, maternal education, and sample. For adolescent Angry/Irritable behavior, results 
indicated a significant main effect of $\mathrm{CU}(\mathrm{F}(1,189)=5.17, \mathrm{p}<.05)$, which was qualified by a CU $\mathrm{X}$ task interaction $(\mathrm{F}(2,188)=4.28, \mathrm{p}<.05)$. The interaction indicated that the association between CU and adolescent Angry/Irritable behavior was most notable in the problem-solving task. This is illustrated in two ways. First, Figure 1 displays the means in adolescent Angry/Irritable behavior across task according to CU (a dichotomous score of CU based on a cut-off score of 7 on the CU scale from the APSD is used for illustrative purposes). The difference between high CU and low CU adolescents in angry/irritable behavior was substantially greater in the problem-solving interaction. Thus, the effect sizes (difference in means/pooled SD) were .36 in the problem-solving task, .18 in the planning task, and .08 in the puzzle task. Alternatively, the correlation between CU traits (as a continuous measure) and adolescent Angry/Irritable behavior was significantly stronger in the problem-solving task ( $\mathrm{r}=$ $.23, \mathrm{p}<.01)$ than the planning $(\mathrm{r}=.08, \mathrm{~ns})$ or puzzle $(\mathrm{r}=.06, \mathrm{~ns})$ tasks controlling for covariates; the difference in correlations was statistically significant using Meng et al.'s (Meng, Rosenthal, \& Rubin, 1992) method for comparing dependent correlations. This within-subjects or crosstask effect was particular to adolescent Angry/Irritable behavior. For adolescent Warmth/Engaged behavior there was not a significant CU X task interaction $(\mathrm{F}(2,188)=.53$, ns $)$. There was a main effect of CU traits on adolescent Warmth/Engaged behavior $(\mathrm{F}(1,189)=7.87$, $\mathrm{p}<.01$ ), indicating that adolescents with CU traits did display less Warmth/Engaged behavior with the parent - to an equal extend across all interaction tasks.

The observation that CU traits were associated with greater within-person or cross-setting variation in Angry/Irritable behavior was particular to the adolescent and was not found in parents. That is, for parent behavior, there was neither a significant main effect of CU nor a CU $\mathrm{X}$ task interaction for maternal Angry/Irritable behavior or Warmth/Engaged behavior. Maternal 
behavior varied across task, but this variation was unrelated to adolescent CU traits.

Specifically, an overall repeated measures effect for Angry/Irritable behavior $(\mathrm{F}(2,218)=20.51$, $\mathrm{p}<.001)$ was accounted for by greater Angry/Irritable behavior in the problem-solving task than in the Planning task $(\mathrm{t}(221)=3.86, \mathrm{p}<.001)$ and in the Puzzle task $(\mathrm{t}(225)=6.13, \mathrm{p}<.001)$, which did not differ from each other $(\mathrm{t}(221)=1.53)$. Maternal Warmth/Engaged behavior did differ across task $(\mathrm{F}(2,218)=71.93, \mathrm{p}<.001)$ : mothers were rated as more warm/engaged in the Problem-Solving task than in the Planning task $(\mathrm{t}(225)=5.09, \mathrm{p}<.001)$ and Puzzle task $(\mathrm{t}(221)=$ 12.14, $\mathrm{p}<.001$ ); levels of Warmth/Engagement were also higher in the Planning task than in the Puzzle task $(\mathrm{t}(221)=7.82, \mathrm{p}<.001)$.

\section{Supplementary analyses}

We did not observe that the findings reported above were substantively different across the three samples of adolescents, i.e., we did not obtain evidence that study membership moderated the findings reported above. Neither did we find that adolescent gender reliably moderated the above findings.

A second series of analyses were undertaken to examine the robustness of the findings on CU. We focus these analyses on the repeated measures analyses assessing adolescent behavior across the three interaction settings because this is the most novel contribution of this research. First, we re-ran the repeated measures analyses with CU from the APSD scale including adolescent self-reported depressive symptoms on the MFQ to test if the emotional regulation indexed by depression accounted for the CU effect on adolescent angry/irritable behavior. It did not. The CU x task interaction in the repeated measures MANOVA was unchanged; and depressive symptoms was not a significant main effect and there was not a significant interaction between depressive symptoms and task in predicting adolescent angry/irritable behavior. 
Second, we re-ran all analyses using the total score of the APSD, which provides a broader measure of psychopathy. The findings mirrored those using the more specific CU scale. Specifically, for adolescent Angry/Irritable behavior, the main effect of total scale APSD was qualified by a APSD X task interaction $(\mathrm{F}(2,188)=4.05, \mathrm{p}<.01)$. (Findings using the regression analyses using the APSD total scale were also comparable to the findings reported above using the more narrow CU scale; details available from the authors.)

Third, as further test of the robustness of the CU effect, we re-ran the models above using the alternative measure of CU from SDQ need guidance here. For this alternative measure of $\mathrm{CU}$, repeated measures analyses (using the same covariates in the analyses of the APSD CU scale) indicated an interaction between SDQ CU symptoms and task, $(\mathrm{F}(2,190)=3.58, \mathrm{p}<.05)$. Follow-up correlation analyses indicated that adolescent SDQ CU traits were significantly associated with Angry/Irritable behavior in the problem-solving task $(r=.23, \mathrm{p}<.01)$ but not in the planning $(\mathrm{r}=.10, \mathrm{~ns})$ or puzzle $(\mathrm{r}=.12, \mathrm{~ns})$ tasks after controlling for covariates. And, as with the APSD CU scale, we found no evidence that the association between SDQ CU traits and adolescent Warmth/Engagement or parent behavior varied across task.

\section{Discussion}

There is considerable clinical and theoretical interest in the possibility that a subset of children and adolescents may be comparatively unresponsive to parenting influences. CU has been proposed as one feature that may distinguish these individuals. The current paper provided multiple tests of that hypothesis in an adolescent sample enriched for CU traits. We found little support for the hypothesis that adolescents with CU traits would be less responsive to caregiving 
than adolescents without CU traits: a) reliable associations between $\mathrm{CU}$ traits and caregiving were found across multiple methods; b) moderation analyses indicated that adolescents with CU traits were not less but perhaps more sensitive to caregiving influences; and, most notably, c) adolescents with CU traits exhibited greater reactivity or within-individual variability in angry/irritable behavior across interaction tasks, with elevations most notable in the high conflict problem-solving interaction.

Before discussing the implications of the study, we first note several limitations. First, the study was composed of cross-sectional data from three pooled samples of adolescents; it is not clear how well these findings may generalize to other samples. Second, we did not have specific affective, cognitive or physiological markers of CU or age of onset, which may be an important subtyping factor (Hyde, Burt, Shaw, Donnellan, \& Forbes, 2015). Another limitation is that we did not analyze specific speech content of the interactions so that, for example, we are unable to determine if the comparatively greater anger/irritability in the problem-solving task among adolescents with CU was accompanied by more or less emotional language. Also, although there is considerable validity data supporting the use of even brief observational assessments (including results from the current study), child behavior assessed from the three assessment settings used in this study can provide only a partial picture of child behavioral functioning. Finally, outcomes other than conduct problems might be moderated by adolescent CU traits; our focus on conduct problems reflects the focus in virtually all of the previous studies (although we note that analyses of other measures of adjustment, e.g., peer relationship quality, yielded no robust evidence of a CU moderation effect; details available from the authors). Set against these limitations are several strengths of the study, including detailed observational methods using multiple interaction settings, clinical diagnostic interviews, parent and teacher 
reports of disruptive behavior, a sample enriched for disruptive behavior and CU traits, and replication across alternative measures of CU traits.

Across the whole sample, the problem-solving interaction was more likely to elicit angry/irritable behavior in adolescents. But the most novel finding in this study was that the problem-solving interaction was significantly more likely to elicit angry/irritable behavior in adolescents with elevated CU traits. That is, rather than appear (more) disengaged or unresponsive to the interaction setting that most closely approximated a parenting task, adolescent with elevated CU traits were instead more angry and irritable than were adolescents low on CU traits. There are several possible explanations for this. It may be that deficits in recognizing fear and empathy in adolescents with $\mathrm{CU}$ traits resulted in greater anger/irritability in the problem-solving setting because of the increased frustration resulting from negotiating and resolving a problem. Related to this explanation is the finding of increased frustration-induced reactive aggression in individuals with CU (Blair, Peschardt, Budhani, Mitchell, \& Pine, 2006). Alternatively, it may be that the problem-solving interaction was particularly effective at evoking proactive, strategic anger in CU adolescents in order to shape the direction of the problemsolving discussion. Whether or not the dyads in which the adolescent had elevated CU traits were less successful in resolving the nominated problems is not clear. Notably, adolescents with elevated CU traits did not elicit significantly more anger/irritability or less warmth/engagement from parents in the problem-solving setting, suggesting that parents of CU adolescents did not find the problem-solving interaction significantly more aversive than parents of non-CU adolescents.

Neurocognitive features of individuals with elevated CU traits are often interpreted to suggest a broad-based, generalized behavioral disturbance. What we found was that adolescents 
with elevated CU traits were instead significantly more sensitive to situational demands and changing contexts; that is, the disturbance, in terms of angry/irritable behavior, was contextsensitive. This observation, which was replicated across measures of CU and the broader construct of psychopathy, underscores the need to consider social and interactional context in developing models for understanding and testing behavioral disturbance and for more routinely incorporating context in clinical assessment - even where the disturbance is presumed to display trait-like stability. An example of variation in behavioral symptoms across assessment context has been offered by Wakschlag and colleagues for conduct disorder (Wakschlag et al., 2008); they found that problems in behavioral regulation in interactions with busy examiner were more predictive of disruptive behavior 1 year later than behavior in alternative observational settings. Another example was provided by Klein and colleagues, who found that intra-individual variability in response best differentiated ADHD from non-clinic youths (Klein, Wendling, Huettner, Ruder, \& Peper, 2006).

The finding that adolescents with elevated CU traits exhibited comparatively greater variability across task - implying greater sensitivity to parenting and interaction context - is consistent with correlation analyses showing that CU traits were robustly associated with parenting measures across a range of methods and regression analyses suggesting that adolescents with CU traits may be more sensitive to parenting influence (although there was a general lack of CU traits moderating the association between parenting and adolescent disruptive behavior). These findings are, however, contrary to some prior studies. Perhaps the strongest contrast to previous studies is that we found no consistent evidence that CU traits moderated the association between parental discipline and conduct problems. There may be methodological factors that may have biased some prior reports, e.g., such as those in which parents provided 
information on parenting and child outcomes and CU traits. Many prior studies were also conducted on younger children. On the other hand, some of the moderation effects detected in this study are consistent with the literature. Specifically, consistent with (Pasalich et al., 2011), we found that adolescents with elevated CU traits were more sensitive to the protective effects of parental warmth/engagement as rated by observers in relation to teacher-rated conduct problems (Table 3).

Quite how these observational findings fit with the substantial set of neuropsychological findings is not yet clear. On one hand, reviews of the neurocognitive and affective responses in individuals with CU (Dawel, O'Kearney, McKone, \& Palermo, 2012; Herpers, Scheepers, Bons, Buitelaar, \& Rommelse, 2014) indicate that the most reliable deficits are in response to and processing of fear and sadness; evidence of other disturbances has been reported but seem less robust. In contrast, the affective challenges in the parent-child problem-solving task tend not to elicit these affects but rather anger and frustration, and particularly the regulation of those emotions - that it why this paradigm has been so central to developmental and clinical studies of disruptive behavior for decades, e.g., (Patterson, 1982). Adolescent behavioral and brain responses to a dynamic, problem-solving task with the parent may not be expected to mimic the kinds of deficits observed in imaging or neurophysiological paradigms used to date. The implication is that findings from imaging and neuropsychological assessments offer only a partial guide for behavioral and brain reactions in intimate interpersonal contexts.

Research suggests that there may be several kinds of factors, some of which may be connected to $\mathrm{CU}$, that may moderate the association between parenting and child adjustment. For example, Kochanska (Kochanska, 1991) found that children's fearfulness moderated the impact of maternal socialization practices in predicting self-regulation and conscience 
development. Other studies suggest that there may be genetic or temperamental characteristics influencing sensitivity to socializing contexts (Belsky \& Pluess, 2009). And, child characteristics that predict variation in response to psychological intervention are now regularly reported (Cleveland et al., 2015; Scott \& O'Connor, 2012; van Ijzendoorn \& BakermansKranenburg, 2015). Collectively, these studies underscore the value in identifying traits that moderate parenting influence beyond $\mathrm{CU}$ traits in order to contribute to a broader debate about susceptibility to environmental context (Ellis, Boyce, Belsky, Bakermans-Kranenburg, \& van Ijzendoorn, 2011).

\section{Applications}

The matter of cross-informant and cross-context discrepancies in child and adolescent behavior has received extensive research attention (De Los Reyes, Henry, Tolan, \& Wakschlag, 2009). Particular emphasis has been on parent and teacher reports of child and adolescent behavioral and emotional problems (Achenbach, McConaughy, \& Howell, 1987), but there are many other examples, such as variability in children's behavior across different family constellations (Deal, Hagan, Bass, Hetherington, \& Clingempeel, 1999; Smetana, Abernethy, \& Harris, 2000; Stroud, Meyers, Wilson, \& Durbin, 2014). One common approach to managing this within-individual variation in behavior is to aggregate behavior across settings to construct a more reliable index of behavior. That supposes that the behaviors across contexts are equally informative; this may not be so. Disruptive behavior, in particular, shows considerable variability across setting and time (Achenbach et al., 1987; Dirks, De Los Reyes, Briggs-Gowan, Cella, \& Wakschlag, 2012); this can be experimentally elicited with clinical observational assessment (De Los Reyes et al., 2009). 
Findings from the current study imply that behavior in the problem-solving conflict task may be most informative for distinguishing adolescents with CU traits. Other studies have also shown that (the same) behavior may carry a different clinical meaning according to the context in which it is assessed. For example, in their study of children with ADHD, Barkley et al (Barkley, 1989) reported that differences between clinic and non-clinic groups are more evident in structured settings; Webster-Stratton found correspondence in conduct problems at home and clinic to be strongest for unstructured settings (Webster-Stratton, 1985); furthermore, a recent parenting RCT demonstrated that improvements in some behavioral aspects of parenting were more apparent in less structured than more structured tasks (O'Connor, Matias, Futh, Tantam, \& Scott, 2013). Problems in applying analogue behavior observations to clinical practice have been discussed for some time (Mash \& Foster, 2001). Research that assesses variability in behavior across different contexts and with varying demands provides useful directions for improving the evidence-based (observational) assessment methods and for illuminating social mechanisms of behavioral disturbance. 
References

Achenbach, T. M., McConaughy, S. H., \& Howell, C. T. (1987). Child/adolescent behavioral and emotional problems: implications of cross-informant correlations for situational specificity. Psychol Bull, 101(2), 213-232.

Angold, A., \& Costello, E. J. (2000). The Child and Adolescent Psychiatric Assessment (CAPA). Journal of the American Academy of Child and Adolescent Psychiatry, 39(1), 39-48. doi: 10.1097/00004583200001000-00015

Angold, A., Costello, E. J., Messer, S. C., Pickles, A., Winder, F., \& Silver, D. (1995). The development of a short questionnaire for use in epidemiological studies of depression in children and adolescents. International Journal of Methods in Psychiatric Research, 5, 237-249.

Barkley, R. A. (1989). Hyperactive girls and boys: stimulant drug effects on mother-child interactions. $J$ Child Psychol Psychiatry, 30(3), 379-390.

Barry, C. T., Frick, P. J., DeShazo, T. M., McCoy, M. G., Ellis, M., \& Loney, B. R. (2000). The importance of callous-unemotional traits for extending the concept of psychopathy to children. J Abnorm Psychol, 109(2), 335-340.

Belsky, J., \& Pluess, M. (2009). Beyond diathesis stress: differential susceptibility to environmental influences. Psychological Bulletin, 135(6), 885-908. doi: 10.1037/a0017376

Blair, R. J., Colledge, E., Murray, L., \& Mitchell, D. G. (2001). A selective impairment in the processing of sad and fearful expressions in children with psychopathic tendencies. J Abnorm Child Psychol, 29(6), 491-498.

Blair, R. J., Peschardt, K. S., Budhani, S., Mitchell, D. G., \& Pine, D. S. (2006). The development of psychopathy. J Child Psychol Psychiatry, 47(3-4), 262-276. doi: 10.1111/j.1469-

7610.2006.01596.x

Blonigen, D. M., Hicks, B. M., Krueger, R. F., Patrick, C. J., \& lacono, W. G. (2006). Continuity and change in psychopathic traits as measured via normal-range personality: a longitudinal-biometric study. J Abnorm Psychol, 115(1), 85-95. doi: 10.1037/0021-843X.115.1.85

Caspi, A., Moffitt, T. E., Morgan, J., Rutter, M., Taylor, A., Arseneault, L., . . Polo-Tomas, M. (2004). Maternal expressed emotion predicts children's antisocial behavior problems: using monozygotic-twin differences to identify environmental effects on behavioral development. Dev Psychol, 40(2), 149-161. doi: 10.1037/0012-1649.40.2.149

2004-11032-003 [pii]

Cleveland, H. H., Schlomer, G. L., Vandenbergh, D. J., Feinberg, M., Greenberg, M., Spoth, R., ... Hair, K. L. (2015). The conditioning of intervention effects on early adolescent alcohol use by maternal involvement and dopamine receptor D4 (DRD4) and serotonin transporter linked polymorphic region (5-HTTLPR) genetic variants. Dev Psychopathol, 27(1), 51-67. doi: $10.1017 /$ S0954579414001291

Dawel, A., O'Kearney, R., McKone, E., \& Palermo, R. (2012). Not just fear and sadness: meta-analytic evidence of pervasive emotion recognition deficits for facial and vocal expressions in psychopathy. Neurosci Biobehav Rev, 36(10), 2288-2304. doi: 10.1016/j.neubiorev.2012.08.006

De Los Reyes, A., Henry, D. B., Tolan, P. H., \& Wakschlag, L. S. (2009). Linking informant discrepancies to observed variations in young children's disruptive behavior. J Abnorm Child Psychol, 37(5), 637652. doi: 10.1007/s10802-009-9307-3

Deal, J. E., Hagan, M. S., Bass, B., Hetherington, E. M., \& Clingempeel, G. (1999). Marital interaction in dyadic and triadic contexts: continuities and discontinuities. Fam Process, 38(1), 105-115.

Dirks, M. A., De Los Reyes, A., Briggs-Gowan, M., Cella, D., \& Wakschlag, L. S. (2012). Annual research review: embracing not erasing contextual variability in children's behavior--theory and utility in 
the selection and use of methods and informants in developmental psychopathology. $J$ Child

Psychol Psychiatry, 53(5), 558-574. doi: 10.1111/j.1469-7610.2012.02537.x

Ellis, B. J., Boyce, W. T., Belsky, J., Bakermans-Kranenburg, M. J., \& van Ijzendoorn, M. H. (2011).

Differential susceptibility to the environment: an evolutionary--neurodevelopmental theory. Dev Psychopathol, 23(1), 7-28. doi: S0954579410000611 [pii]

\section{$10.1017 /$ S0954579410000611}

Fisher, L., \& Blair, R. J. (1998). Cognitive impairment and its relationship to psychopathic tendencies in children with emotional and behavioral difficulties. J Abnorm Child Psychol, 26(6), 511-519.

Frick, P. J., \& Hare, R.D. (2001). The antisocial process screening device. Toronto: Multi-Health Systems.

Frick, P. J., Christian, R. E., \& Wootton, J. M. (1999). Age trends in the association between parenting practices and conduct problems. Behavior Modification. Behavior Modification, 23, 106-128.

Frick, P. J., Kimonis, E. R., Dandreaux, D. M., \& Farell, J. M. (2003). The 4 year stability of psychopathic traits in non-referred youth. Behav Sci Law, 21(6), 713-736. doi: 10.1002/bsl.568

Frick, P. J., Ray, J. V., Thornton, L. C., \& Kahn, R. E. (2014). Can callous-unemotional traits enhance the understanding, diagnosis, and treatment of serious conduct problems in children and adolescents? A comprehensive review. Psychol Bull, 140(1), 1-57. doi: 10.1037/a0033076

Frick, P. J., \& Viding, E. (2009). Antisocial behavior from a developmental psychopathology perspective. Dev Psychopathol, 21(4), 1111-1131. doi: 10.1017/S0954579409990071

Goodman, A., \& Goodman, R. (2009). Strengths and difficulties questionnaire as a dimensional measure of child mental health. J Am Acad Child Adolesc Psychiatry, 48(4), 400-403. doi: 10.1097/CHI.0b013e3181985068

S0890-8567(09)60047-2 [pii]

Goodman, R., \& Scott, S. (1999). Comparing the Strengths and Difficulties Questionnaire and the Child Behavior Checklist: is small beautiful? J Abnorm Child Psychol, 27(1), 17-24.

Hagan, M. S., Hollier, E. A., O'Connor, T. G., \& Eisenberg, N. (1992). Parent-child relationships in nondivorced, divorced single-mother, and remarried families. In E. M. Hetherington \& G. Clingempeel (Eds.), Coping with marital transitions: A family systems perspective. (Vol. 57, pp. 94-148): Monographs of the Society for Research in Child Development.

Hawes, D. J., \& Dadds, M. R. (2007). Stability and malleability of callous-unemotional traits during treatment for childhood conduct problems. J Clin Child Adolesc Psychol, 36(3), 347-355. doi: 10.1080/15374410701444298

Herpers, P. C., Scheepers, F. E., Bons, D. M., Buitelaar, J. K., \& Rommelse, N. N. (2014). The cognitive and neural correlates of psychopathy and especially callous-unemotional traits in youths: a systematic review of the evidence. Dev Psychopathol, 26(1), 245-273. doi: 10.1017/S0954579413000527

Hetherington, E. M., \& Clingempeel, W. G. (1992). Coping with marital transitions: a family systems perspective. Monographs of the Society for Research in Child Development, 57(2-3).

Hyde, L. W., Burt, S. A., Shaw, D. S., Donnellan, M. B., \& Forbes, E. E. (2015). Early starting, aggressive, and/or callous-unemotional? Examining the overlap and predictive utility of antisocial behavior subtypes. J Abnorm Psychol, 124(2), 329-342. doi: 10.1037/abn0000029

Joseph, M. A., O'Connor, T. G., Briskman, J. A., Maughan, B., \& Scott, S. (2014). The formation of secure new attachments by children who were maltreated: an observational study of adolescents in foster care. Development and Psychopathology, 26(1), 67-80. doi: 10.1017/S0954579413000540

Klein, C., Wendling, K., Huettner, P., Ruder, H., \& Peper, M. (2006). Intra-subject variability in attentiondeficit hyperactivity disorder. Biol Psychiatry, 60(10), 1088-1097. doi:

10.1016/j.biopsych.2006.04.003 
Kochanska, G. (1991). Socialization and temperament in the development of guilt and conscience. Child Dev, 62(6), 1379-1392.

Kolko, D. J., \& Pardini, D. A. (2010). ODD dimensions, ADHD, and callous-unemotional traits as predictors of treatment response in children with disruptive behavior disorders. J Abnorm Psychol, 119(4), 713-725. doi: 10.1037/a0020910

Kroneman, L. M., Hipwell, A. E., Loeber, R., Koot, H. M., \& Pardini, D. A. (2011). Contextual risk factors as predictors of disruptive behavior disorder trajectories in girls: the moderating effect of callousunemotional features. J Child Psychol Psychiatry, 52(2), 167-175. doi: 10.1111/j.14697610.2010.02300.x

Larsson, H., Andershed, H., \& Lichtenstein, P. (2006). A genetic factor explains most of the variation in the psychopathic personality. J Abnorm Psychol, 115(2), 221-230. doi: 10.1037/0021843X.115.2.221

Loney, B. R., Butler, M. A., Lima, E. N., Counts, C. A., \& Eckel, L. A. (2006). The relation between salivary cortisol, callous-unemotional traits, and conduct problems in an adolescent non-referred sample. J Child Psychol Psychiatry, 47(1), 30-36. doi: 10.1111/j.1469-7610.2005.01444.x

Marsh, A. A., Finger, E. C., Mitchell, D. G., Reid, M. E., Sims, C., Kosson, D. S., . . Blair, R. J. (2008). Reduced amygdala response to fearful expressions in children and adolescents with callousunemotional traits and disruptive behavior disorders. Am J Psychiatry, 165(6), 712-720. doi: 10.1176/appi.ajp.2007.07071145

Mash, E. J., \& Foster, S. L. (2001). Exporting analogue behavioral observation from research to clinical practice: useful or cost-defective? Psychol Assess, 13(1), 86-98.

Mcara, L., McVie, S. (2005). The usual suspects? Street-life, young people and the police. . Criminal Justice, 5, 5-36.

McMahon, R. J., Witkiewitz, K., \& Kotler, J. S. (2010). Predictive validity of callous-unemotional traits measured in early adolescence with respect to multiple antisocial outcomes. J Abnorm Psychol, 119(4), 752-763. doi: 10.1037/a0020796

McMahon, R. J., Witkiewitz, K., Kotler, J. S., \& Conduct Problems Prevention Research, G. (2010). Predictive validity of callous-unemotional traits measured in early adolescence with respect to multiple antisocial outcomes. J Abnorm Psychol, 119(4), 752-763. doi: 10.1037/a0020796

Meng, X.-I., Rosenthal, R., \& Rubin, D. B. (1992). Comparing correlated correlation coefficients. Psychological Bulletin, 111, 172-175.

Musser, E. D., Backs, R. W., Schmitt, C. F., Ablow, J. C., Measelle, J. R., \& Nigg, J. T. (2011). Emotion regulation via the autonomic nervous system in children with attention-deficit/hyperactivity disorder (ADHD). J Abnorm Child Psychol, 39(6), 841-852. doi: 10.1007/s10802-011-9499-1

O'Connor, T. G., Matias, C., Futh, A., Tantam, G., \& Scott, S. (2013). Social learning theory parenting intervention promotes attachment-based caregiving in young children: randomized clinical trial. Journal of clinical child and adolescent psychology : the official journal for the Society of Clinical Child and Adolescent Psychology, American Psychological Association, Division 53, 42(3), 358370. doi: 10.1080/15374416.2012.723262

Oxford, M., Cavell, T. A., \& Hughes, J. N. (2003). Callous/unemotional traits moderate the relation between ineffective parenting and child externalizing problems: a partial replication and extension. J Clin Child Adolesc Psychol, 32(4), 577-585. doi: 10.1207/S15374424JCCP3204_10

Pardini, D. A., \& Fite, P. J. (2010). Symptoms of conduct disorder, oppositional defiant disorder, attention-deficit/hyperactivity disorder, and callous-unemotional traits as unique predictors of psychosocial maladjustment in boys: advancing an evidence base for DSM-V. J Am Acad Child Adolesc Psychiatry, 49(11), 1134-1144. doi: 10.1016/j.jaac.2010.07.010 
Pardini, D. A., Lochman, J. E., \& Powell, N. (2007). The development of callous-unemotional traits and antisocial behavior in children: are there shared and/or unique predictors? J Clin Child Adolesc Psychol, 36(3), 319-333. doi: 10.1080/15374410701444215

Pasalich, D. S., Dadds, M. R., Hawes, D. J., \& Brennan, J. (2011). Do callous-unemotional traits moderate the relative importance of parental coercion versus warmth in child conduct problems? An observational study. J Child Psychol Psychiatry, 52(12), 1308-1315. doi: 10.1111/j.14697610.2011.02435.x

Patterson, G. R. (1982). Coercive Family Process. Eugene, OR: Castalia.

Scott, S., Briskman, J., Woolgar, M., Humayun, S., \& O'Connor, T. G. (2011). Attachment in adolescence: overlap with parenting and unique prediction of behavioural adjustment. Journal of child psychology and psychiatry, and allied disciplines, 52(10), 1052-1062. doi: 10.1111/j.14697610.2011.02453.x

Scott, S., \& O'Connor, T. G. (2012). An experimental test of differential susceptibility to parenting among emotionally-dysregulated children in a randomized controlled trial for oppositional behavior. Journal of child psychology and psychiatry, and allied disciplines, 53(11), 1184-1193. doi: 10.1111/j.1469-7610.2012.02586.x

Scott, S., Spender, Q., Doolan, M., Jacobs, B., \& Aspland, H. (2001). Multicentre controlled trial of parenting groups for childhood antisocial behaviour in clinical practice. BMJ, 323(7306), 194198.

Scott, S., Sylva, K., Doolan, M., Price, J., Jacobs, B., Crook, C., \& Landau, S. (2010). Randomised controlled trial of parent groups for child antisocial behaviour targeting multiple risk factors: the SPOKES project. J Child Psychol Psychiatry, 51(1), 48-57. doi: JCPP2127 [pii]

10.1111/j.1469-7610.2009.02127.x

Smetana, J. G., Abernethy, A., \& Harris, A. (2000). Adolescent-parent interactions in middle-class African American families: longitudinal change and contextual variations. J Fam Psychol, 14(3), 458-474.

Smith, D. J., and McVie, S. (2003). Theory and method in the Edinburgh study of youth transitions and crime. British Journal of Criminology, 43, 169-195.

Spain, S. E., Douglas, K. S., Poythress, N. G., \& Epstein, M. (2004). The relationship between psychopathic features, violence and treatment outcome: the comparison of three youth measures of psychopathic features. Behav Sci Law, 22(1), 85-102. doi: 10.1002/bsl.576

Stroud, C. B., Meyers, K. M., Wilson, S., \& Durbin, C. E. (2014). Marital Quality Spillover and Young Children's Adjustment: Evidence for Dyadic and Triadic Parenting as Mechanisms. J Clin Child Adolesc Psychol, 1-14. doi: 10.1080/15374416.2014.900720

Sylvers, P. D., Brennan, P. A., \& Lilienfeld, S. O. (2011). Psychopathic traits and preattentive threat processing in children: a novel test of the fearlessness hypothesis. Psychol Sci, 22(10), 12801287. doi: $10.1177 / 0956797611420730$

Tuvblad, C., Wang, P., Bezdjian, S., Raine, A., \& Baker, L. A. (2015). Psychopathic personality development from ages 9 to 18: Genes and environment. Dev Psychopathol, 1-18. doi: $10.1017 /$ S0954579415000267

van ljzendoorn, M. H., \& Bakermans-Kranenburg, M. J. (2015). Genetic differential susceptibility on trial: meta-analytic support from randomized controlled experiments. Dev Psychopathol, 27(1), 151162. doi: $10.1017 / \mathrm{S} 0954579414001369$

van Zwieten, A., Meyer, J., Hermens, D. F., Hickie, I. B., Hawes, D. J., Glozier, N., . . Guastella, A. J. (2013). Social cognition deficits and psychopathic traits in young people seeking mental health treatment. PLoS One, 8(7), e67753. doi: 10.1371/journal.pone.0067753 
Viding, E., Jones, A. P., Frick, P. J., Moffitt, T. E., \& Plomin, R. (2008). Heritability of antisocial behaviour at 9: do callous-unemotional traits matter? Developmental science, 11(1), 17-22. doi: 10.1111/j.1467-7687.2007.00648.x

Viding, E., Sebastian, C. L., Dadds, M. R., Lockwood, P. L., Cecil, C. A., De Brito, S. A., \& McCrory, E. J. (2012). Amygdala response to preattentive masked fear in children with conduct problems: the role of callous-unemotional traits. Am J Psychiatry, 169(10), 1109-1116. doi: 10.1176/appi.ajp.2012.12020191

Wakschlag, L. S., Briggs-Gowan, M. J., Hill, C., Danis, B., Leventhal, B. L., Keenan, K., . . Carter, A. S. (2008). Observational Assessment of Preschool Disruptive Behavior, Part II: validity of the Disruptive Behavior Diagnostic Observation Schedule (DB-DOS). J Am Acad Child Adolesc Psychiatry, 47(6), 632-641. doi: 10.1097/CHI.0b013e31816c5c10

S0890-8567(09)62437-0 [pii]

Waller, R., Gardner, F., Hyde, L. W., Shaw, D. S., Dishion, T. J., \& Wilson, M. N. (2012). Do harsh and positive parenting predict parent reports of deceitful-callous behavior in early childhood? J Child Psychol Psychiatry, 53(9), 946-953. doi: 10.1111/j.1469-7610.2012.02550.x

Waller, R., Gardner, F., Shaw, D. S., Dishion, T. J., Wilson, M. N., \& Hyde, L. W. (2014). CallousUnemotional Behavior and Early-Childhood Onset of Behavior Problems: The Role of Parental Harshness and Warmth. J Clin Child Adolesc Psychol. doi: 10.1080/15374416.2014.886252

Webster-Stratton, C. (1985). Comparisons of behavior transactions between conduct-disordered children and their mothers in the clinic and at home. J Abnorm Child Psychol, 13(2), 169-183.

Wootton, J. M., Frick, P. J., Shelton, K. K., \& Silverthorn, P. (1997). Ineffective parenting and childhood conduct problems: the moderating role of callous-unemotional traits. J Consult Clin Psychol, 65(2), 301-308.

Wymbs, B. T., McCarty, C. A., King, K. M., McCauley, E., Vander Stoep, A., Baer, J. S., \& Waschbusch, D. A. (2012). Callous-unemotional traits as unique prospective risk factors for substance use in early adolescent boys and girls. J Abnorm Child Psychol, 40(7), 1099-1110. doi: 10.1007/s10802-0129628-5

Yeh, M. T., Chen, P., Raine, A., Baker, L. A., \& Jacobson, K. C. (2011). Child psychopathic traits moderate relationships between parental affect and child aggression. J Am Acad Child Adolesc Psychiatry, 50(10), 1054-1064. doi: 10.1016/j.jaac.2011.06.013 
Table 1. Sample characteristics: Means (SD) or percentages (n) across sample.

$\begin{array}{llllll} & \text { Total } & \text { Clinic-referred } & \text { High-risk community } & \text { Foster } & \underline{\text { F/Chi-square (df) }} \\ & \mathrm{n}=271 & \mathrm{n}=107 & \mathrm{n}=102 & \mathrm{n}=62 & \\ \text { Child age } & 12.56(1.97) & 13.26(1.81)^{\mathrm{a}} & 11.04(.89)^{\mathrm{b}} & 13.86(1.95)^{\mathrm{a}} & 79.95(2,268)^{* * *} \\ \text { Child gender (male) } & 68 \%(184) & 76 \%(81)^{\mathrm{a}} & 69 \%(70)^{\mathrm{a}, \mathrm{b}} & 53 \%(33)^{\mathrm{b}} & 8.93(2)^{*} \\ \text { Maternal education§ } & 40 \%(109) & 53 \%(52)^{\mathrm{a}} & 37 \%(37)^{\mathrm{b}} & 32 \%(20)^{\mathrm{b}} & 7.95(2)^{*} \\ \text { Minority status } & 34 \%(86) & 17 \%(16)^{\mathrm{a}} & 41 \%(101)^{\mathrm{b}} & 47 \%(29)^{\mathrm{b}} & 19.75(2)^{* * *} \\ \text { Single-parent status } & 34 \%(92) & 42 \%(45) & 29 \%(30) & 27 \%(17) & 5.22(2) \\ \text { ODD diagnosis } & 17 \%(44) & 27 \%(28)^{\mathrm{a}} & 10 \%(10)^{\mathrm{b}} & 10 \%(6)^{\mathrm{b}} & 12.43(2)^{* *} \\ \text { APSD CU } & 4.26(2.46) & 5.36(2.42)^{\mathrm{a}} & 2.82(1.97)^{\mathrm{c}} & 4.46(2.02)^{\mathrm{b}} & 31.49(2,232)^{* * *} \\ \text { APSD CU 7\% } & 19 \% & 30 \% & 7.1 \% & 15 \% & 18.09(2)^{* * *}\end{array}$

Note: The F/chi-square tests the hypothesis that the variable is not significantly different across the three samples. Means or percentiles not sharing a superscript are significantly different from each other at $\mathrm{p}<.05$ in post hoc analyses using Bonferroni correction. § percent (n) who left school by age 16 years. Three of the above measures had missing data: for ODD, $n=262 ;$ for APSD, $\mathrm{n}=235$; for mother-reported minority status, $\mathrm{n}=257 . * \mathrm{p}<.05, * * \mathrm{p}<.01, * * * \mathrm{p}<.001$. 
Table 2. Associations between Parent-Child Relationship Measures and Adolescent CU Traits CU Traits

$\underline{\mathrm{r} \quad \text { Adjusted }^{\mathrm{a}}}$

Observational data

Parent behavior

$\begin{array}{lll}\text { Angry/Irritable } & .12 & .13 \\ \text { Warmth/Engaged } & -.11 & -.03\end{array}$

Adolescent behavior

Angry/Irritable

$.28 * * * \quad .19 * *$

Warmth/Engaged

$-.22 * * \quad-.16 *$

$\underline{\text { Parent Interview }}$

Positive comments

$-.38 * * * \quad-.19 * *$

Negative comments

$.40 * * * \quad .15^{*}$

Pos/Neg ratio

$-.41 * * * \quad-.23 * * *$

Questionnaire

Adolescent report

Poor monitoring $\quad .24 * * * \quad .12$

Inconsistent discipline $\quad .16^{*} \quad .07$

Positive parenting $\quad-.16^{*} \quad-.14^{*}$

Parent report

Poor monitoring $\quad .31 * * * \quad .11$

Inconsistent discipline $\quad .19 * * \quad-.05$

Positive parenting $\quad-.22 * * * \quad-.27 * * *$

Note: ${ }^{a}$ controlling for parent reported conduct problems on the SDQ. * $\mathrm{p}<.05, * * \mathrm{p}<.01, * * *$ $\mathrm{p}<.001$. 
Table 3. Regression Analyses Testing CU Moderation of Parent-Child Relationship Measures on Conduct Problems

$\begin{array}{llll}\text { Parent SDQ } & \text { Parent CAPA } & \text { Teacher SDQ } & \text { Adolescent } \\ \underline{\text { conduct }} & \underline{\text { ODD symptoms }} & \underline{\text { conduct }} & \underline{\text { SRD }}\end{array}$

$\begin{array}{llllllll}\text { B SE } & b & \text { B SE } & \text { b } & \text { B SE } & \text { b } & \text { B SE } & \text { b }\end{array}$

$\underline{\text { Observational data }}$

Maternal behavior

1. Warmth/Engaged

$\begin{array}{llllllll}.00(.34) & .00 & -.03(.30) & -.01 & .49(.42) & .15 & -.58(2.47) & -.03 \\ .75(.29) & .78^{*} & .61(.25) & .80 & 1.24(.34) & 1.34 * * * & -1.67(2.09) & -.30 \\ -.05(.07) & -.21 & -.08(.07) & -.42 & -.25(.09) & -1.06 * * & .39(.54) & .28\end{array}$

2. Angry/Irritable

$\begin{array}{lllllll}-.40(.44) & -.12 & -.08(.39) & -.03 & -.08(.57) & -.02\end{array}$

$1.34(3.13) \quad .08$

Adolescent CU traits

$.50 * * * .29(.12)$

$.38 * \quad .12(.17)$

$.50(.95) \quad .09$

Interaction

$.06(.09)$

$.13 \quad .02(.08)$

$.04 \quad .12(.11) \quad .26$

$-.49(.60) \quad-.20$

Questionnaire: parent report

$\begin{array}{lllllllll}\text { 3. Poor monitoring } & .08(.05) & .22 & .03(.05) & .10 & .02(.06) & .06 & 1.35(.33) & .66 * * * \\ \text { Adolescent CU traits } & .46(.10) & .49 * * * .36(.10) & .46^{* * *}-.09(.14) & -.10 & 1.04(.75) & .20 \\ \text { Interaction } & .00(.01) & .06 & .00(.01) & -.10 & .02(.01) & .49 * & -.14(.06) & -.54 *\end{array}$




$\begin{array}{lcccccccc}\text { 4. Positive parenting } & .10(.08) & .14 & -.02(.07) & -.03 & .15(.10) & .23 & .24(.54) & .07 \\ \text { Adolescent CU traits } & .66(.29) & .70^{*} & .02(.26) & .02 & .54(.36) & .58 & .64(1.91) & .13 \\ \text { Interaction } & -.01(.01) & -.10 & .02(.01) & .42 & -.01(.02) & -.25 & -.54(.10) & -.18\end{array}$

Adolescent Questionnaire

$\begin{array}{lcccccccc}\text { 5. Poor monitoring } & .00(.04) & .00 & -.01(.04) & -.03 & .02(.05) & .07 & .62(.27) & .34 * \\ \text { Adolescent CU traits } & .42(.09) & .44^{* * *} .25(.08) & .33^{* *} & .25(.11) & .27 * & .48(.66) & .09 \\ \text { Interaction } & .01(.01) & .21 & .01(.01) & .13 & .00(.01) & .03 & -.08(.05) & -.29 \\ \text { 6. Positive parenting } & .03(.06) & .05 & -.05(.05) & -.13 & .04(.07) & .07 & -.56(.42) & -.20 \\ \text { Adolescent CU traits } & .61(.20) & .65 * * & .16(.18) & .20 & .23(.25) & .25 & -1.81(1.42) & -.34 \\ \text { Interaction } & .00(.01) & -.08 & .01(.01) & .23 & .00(.01) & .06 & .10(.08) & .32\end{array}$

$\underline{\text { Maternal Interview }}$

\begin{tabular}{|c|c|c|c|c|c|c|c|}
\hline 7. FMSS Positive/Negative & $-.09(.07)$ & -.11 & $-.01(.06)$ & -.02 & $.07(.10)$ & .07 & $-.58(.45)$ \\
\hline Adolescent CU traits & $.54(.08)$ & $.56 * * *$ & $.39(.07)$ & $.48 * * *$ & $.32(.10)$ & $.32 * *$ & $-.70(.50)$ \\
\hline Interaction & $-.03(.02)$ & -.11 & $-.06(.02)$ & $-.24 * *$ & $-.06(.03)$ & -.19 & $.21(.14)$ \\
\hline
\end{tabular}


Note: Results from 7 separate regression models for four outcome measures of adolescent conduct/disruptive according to parent, teacher and adolescent self-report; estimates are reported for only the measure of parenting, adolescent CU traits, and the interaction from each model. Models control for child age and gender, sample, and parent education. FMSS Positive/Negative is the ratio of positive to negative comments on the five minute speech sample. $* \mathrm{p}<.05, * * \mathrm{p}<.01, * * * \mathrm{p}<.001$. 
$\underline{\text { Table 4. Means (SD) of Adolescent and Parent Behavior Across Interaction Tasks }}$

$\begin{array}{llllll} & \text { Planning } & \text { Problem-Solving } & \text { Puzzle } & \mathrm{F}(2,218) & \mathrm{p} \\ \text { Child Warmth/Engaged } & 2.86(.81) & 2.82(.89) & 2.85(.71) & .33 & .72 \\ \text { Child Angry/Irritable } & 1.27(.59)^{\mathrm{a}} & 1.82(.93)^{\mathrm{b}} & 1.34(.63)^{\mathrm{a}} & 51.00 & <.001 \\ \text { Mother Warmth/Engaged } & 3.60(.73)^{\mathrm{a}} & 3.80(.74)^{\mathrm{b}} & 3.22(.78)^{\mathrm{c}} & 71.93 & <.001 \\ \text { Mother Angry/Irritable } & 1.20(.55)^{\mathrm{a}} & 1.49(.79)^{\mathrm{b}} & 1.27(.60)^{\mathrm{a}} & 20.51 & <.001\end{array}$

Note: Means not sharing a superscript are significantly different from each other at $\mathrm{p}<.05$. 
Appendix I. Correlations Between Parent-Child Relationship Measures and Conduct Problems and CU Traits

\begin{tabular}{llll} 
CU & $\begin{array}{l}\text { Parent Reported } \\
\text { Conduct }\end{array}$ & $\begin{array}{l}\text { Teacher Reported } \\
\text { ODD }\end{array}$ & $\begin{array}{l}\text { Adolescent Reported } \\
\text { Conduct }\end{array}$ \\
\hline
\end{tabular}

$\underline{\text { Observational data }}$

Parent behavior

Angry/Irritable

Warmth/Engaged

Adolescent behavior

Angry/Irritable

Warmth/Engaged

Parent Interview

Positive/Negative

Comment Ratio

Questionnaire

Adolescent report

Poor monitoring

Inconsistent discipline

$\begin{array}{lllll}.12+ & .03 & .00 & .22 * * & -.03 \\ -.11 & -.13+ & -.10 & -.24 * * * & .20 \\ .28 * * * & .21 * * * & .25 * * * & .28 * * * & \\ -.22 * * & -.14+ & -.14 * & -.22 * * & .04 \\ & & & & -.03\end{array}$

Positive parenting

Parent report

Poor monitoring

Inconsistent discipline

Positive parenting

$\begin{array}{lllll}-.41 * * * & -.39 * * * & -.34 * * * & -.17 * & -.08 \\ & & & & \\ .24 * * * & .26 * * * & .12 & .20 * * & .24 * * * \\ .16 * & .17 * & .08 & .06 & .11+ \\ -.16 * & -.08 & -.07 & .01 & -.10 \\ .31 * * * & .37 * * * & .14 * & .28 * * * & .31 * * * \\ .19 * * & .37 * * * & .36 * * * & .15 * & .10 \\ -.22 * * * & -.03 & .05 & .06 & -.02\end{array}$

Note: $+\mathrm{p}<.10, * \mathrm{p}<.05, * * \mathrm{p}<.01, * * * \mathrm{p}<.001$. 
Appendix II. Correlations Between Adolescent and Parent Behavior Across Tasks

\section{Child Behavior}

$\begin{array}{llllllllllll}1 & 2 & 3 & 4 & 5 & 6 & 7 & 8 & 9 & 10 & 11 & 12\end{array}$

1. Angry/Irritable Planning $\quad 1.0$

2. Angry/Irritable Problem-Solving $\quad .51 \quad 1.0$

3. Angry/Irritable Puzzle

$.39 \quad .37 \quad 1.0$

4. Warmth Planning

5. Warmth Problem-Solving

$\begin{array}{lll}-.38 & -.24 & -.08\end{array}$

$-.31--.38--.18-.67$

6. Warmth Puzzle

$\begin{array}{llllll}-.35 & -.31 & -.35 & .51 & .59 & 1.0\end{array}$

Parent behavior

$\begin{array}{llllllll}\text { 7. Angry/Irritable Planning } & .14 & .04 & .07 & -.01 & -.04 & -.05 & 1.0\end{array}$

8. Angry/Irritable Problem-Solving $\quad .01 \quad \begin{array}{lllllll} & .28 & .05 & .02 & -.10 & -.07 & 54\end{array}$

9. Angry/Irritable Puzzle

10. Warmth Planning

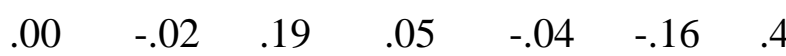

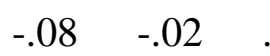

Warmth Problem-Solving

$\begin{array}{lll}-.11 & -.15 & -.05 \\ -.19 & -.12 & -.23\end{array}$

$-.19-.12-.23$

$.47 \quad .31$

1.0

$\begin{array}{lllll}42 & 37 & -30 & -.20 & 1.0\end{array}$

$\begin{array}{lllllll}.42 & .37 & -.30 & -.20 & -.14 & 1.0\end{array}$

$\begin{array}{lllllll}.49 & .42 & -.33 & -.48 & -.26 & .68 & 1.0\end{array}$

12. Warmth Puzzle

$.26 \quad .29$

Note: Correlations $\geq+/-.23$ are significant at $\mathrm{p}<.001$; correlations $\geq+/-.18$ are significant at $\mathrm{p}<.01$; correlations $\geq+/-.14$ are significant at $\mathrm{p}<.01$. 
Figure 1. Adolescent Angry/Irritable Behavior Across Task According to CU

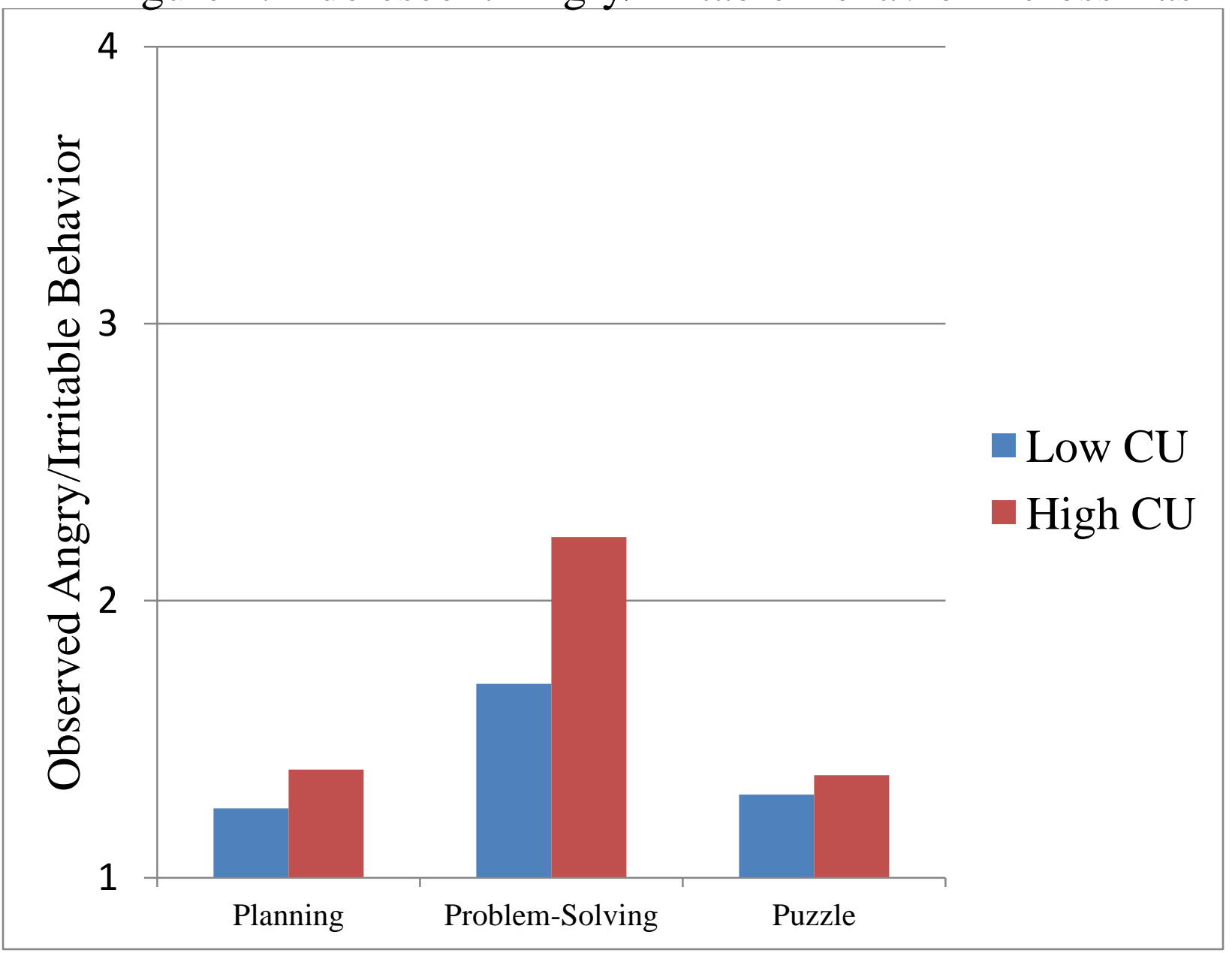

